\title{
Interpreting the Virtues of Mindfulness and Compassion: Contemplative Practices and Virtue-Oriented Business Ethics
}

\author{
Kevin T. Jackson ${ }^{1,2}$ (D)
}

Received: 19 February 2018 / Accepted: 29 May 2018 / Published online: 5 June 2018

(C) Springer International Publishing AG, part of Springer Nature 2018

\begin{abstract}
The article aims to provide a standpoint from which to critically address two broad concerns. The first concern surrounds a naïve view of mindfulness, which takes it as a given that it is a good thing to cultivate mindfulness and attendant qualities like compassion because these virtues are key to improving the quality of life and bettering effective decisionmaking within business. Yet the virtue of mindfulness has roots in religious and spiritual traditions, and the virtue of compassion is complex and contextual; neither of these virtues operate in a vacuum. Nor do they function independently from other virtues and values. Reasonable people of goodwill possessing the virtues of mindfulness and compassion in good measure, may nevertheless strongly disagree about what the compassionate, mindful thing to do is, particularly in a business setting. It is, moreover, conceivable that intensively cultivating mindfulness and compassion could lead one to reject altogether the "dog-eat dog" culture of competitive business that draws upon selective features of mindfulness meditation that lie in the corporate comfort zone yet which are not especially countercultural from a religious or spiritual vantage point. The second concern is that Western virtue-based business ethics is largely confined to academic philosophical theories. As such, virtue-driven business ethics is often more centered around developing theoretical wisdom than developing "hard core" practical wisdom earned through yoga asanas, meditation, chanting, and breathing, whereas for contemplative practices the reverse is the case, with practical wisdom ("knowing how-to") emphasized over theoretical wisdom ("knowing that"). Accordingly, the article examines prospects for cross-fertilization between, on the one hand, mindfulness and compassion interpreted as virtues in Eastern contemplative practices, and on the other hand, mindfulness and compassion as interpreted within Western virtue-oriented business ethics. Illuminating a pathway for such interpretative
\end{abstract}

Kevin T. Jackson

prof.kevin.jackson@gmail.com

2 Janssen Family Chair in Mindfulness and CSR, Solvay Brussels School of Economics and Management, Université libre de Bruxelles, Brussels, Belgium 
cross-pollination calls for an appropriate conceptual frame of reference that the article organizes around a set of interconnected themes. The first theme is that mindfulness and compassion represent key virtues within contemplative practices. This indicates a promising touchpoint between Eastern and Western traditions: their respective focus upon character, inner states, intrinsic motivation, and self-improvement toward ethicality in the world. The second theme is that such virtues in Eastern contemplative practices, as well as character traits integral to Western virtue-oriented approaches, denote contested "normative-interpretive" concepts that engage philosophical debate rather than indisputable empirical-criterial concepts that can be taken at face-value. The third theme advocates moving beyond behaviorist and neuropsychological accounts of virtue, approaching character traits of Eastern contemplative practice and Western virtue ethics through nonscientific inquiry into normative interpretive questions concerning such virtues (questions about meaning, responsibility, the nature of the self, reasons for acting). This supports debate over competing views of the nature, purpose, cultivation, and cultural context of mindfulness, compassion, and other virtues - issues arising as mindfulness enters the business management sphere - to be conducted on normative grounds. With the background conceptual framework established, the article presents key points about the prospects for cross-fertilization between virtue ethics and contemplative practice, and why it matters, with reference to business ethics.

Keywords Mindfulness - Compassion · Contemplative practices · Virtue-oriented business ethics

\section{Introduction}

An emerging trend in business management is to incorporate contemplative practices such as mindfulness meditation and yoga in the workplace. Recently the New York Times showcased David Gelles, author of Mindful Work, who praised Aetna CEO Mark Bertolini for welcoming meditation and yoga, and for incorporating spiritually-friendly practices into workplace wellness programs at his company (Gelles 2015b). In a widely acclaimed management book, Gelles offers a detailed journalistic account of the emerging corporate mindfulness movement. Together with Aetna, the roster of companies delivering mindfulness and meditation programs for their workforce is growing: Apple, General Mills, Google, Green Mountain Coffee, LinkedIn, Monsanto, Newman's Own Organics, and Prana, to name just a few (Gelles 2015a).

Scientifically-controlled research studies indicate that mindfulness meditation increases positive feeling and reduces anxiety (Siegel 2010; Brown and Ryan 2003). Empirical studies reveal increased brain and immune functioning following an eight-week introduction to mindfulness through an educational program fashioned after a prototype created for a variety of occupations (Kabat-Zinn et al. 1992). These findings and other similar research initiatives add empirical support to a long tradition of contemplative practices having religious and philosophical anchorings, along with associated anecdotal indications of the success of such practices in training mind, body and spirit.

Some scholarship confirms a set of propositions to the effect that promoting contemplative practices in both business education and the workplace has the potential to increase awareness of the intricate humanity at the core of business and economic pursuits; to enlarge the role of practical wisdom in managerial decisionmaking; and to nurture higher-order dispositions for leadership, innovation, and overall fulfillment as a human being (Corner 2009; Pruzan 2011; 
Gelles 2015a). Moreover, pointing to the popularity of Google's Search Inside Yourself program, which coaches employees on their mindfulness skills, David Destino, a professor of psychology at Northeastern University, recently adduced findings that mindfulness meditation fosters compassion, as evidenced by diminutions of both the "bystander effect" and "compassion fatigue" in research subjects that underwent meditation-based training (Destino 2015).

The compendium of secularized methods being adopted by the modern mindfulness movement focuses on increasing some of the same human capacities cultivated in religious and spiritual traditions - capacities for increased compassion, sharpened concentration, deep reflection and enhanced epistemological processing; ways of expanding awareness and amplifying the sense of caring for others grounded in contemplative experience (Dalai Lama 2011).

Alongside the attention being paid to Eastern contemplative practices in the business and management context, there has been as well a steady uptick in scholarly attention extended to Western virtue approaches to business ethics (Alzola 2012, 2015, 2017; Arjoon et al. 2015; Audi 2012; Sison and Fontrodona 2012; Beadle and Moore 2006; Whetstone 2001). The recent intensification of such virtue-oriented business ethics scholarship was preceded by a recognition of the essential part played by the concepts of character and virtue throughout the field of business ethics (Moore 2005; Koehn 1998; Moberg 1999; Solomon 1997). Within the Western virtue approach to business ethics a viewpoint has developed, drawing upon ideas of Alasdair MacIntyre (MacIntyre 2007), that calls attention to the potential benefits of cultivating internal goods of excellence as a hedge against the perils of too much emphasis being placed on external goods of effectiveness (such as reputation and profit) which, it has been argued, may corrupt the character of organizations from the inside (Moore 2005, 660-661; Moore 2015, 104). Similarly, another path in virtue-oriented business ethics scholarship, the so-called non-reductive approach, emphasizes the vital importance of understanding inner states - attitudes, beliefs, desires, emotions, and inclinations - in accounting for the character of virtuous moral agents in organizational contexts (Alzola 2015). The latter two directions in virtue-based business ethics seem to possess general theoretical compatibility with the characteristic inward-pointed starting point of contemplative practices.

The overarching intent of this article is to provide a standpoint from which to critically address two broad concerns in light of the confluence of the aforementioned emerging trends (rising interest in the benefits of mindfulness, particularly for business; mounting emphasis on the virtue approach in business ethics, particularly the turn toward internal goods and inner states). The first broad concern surrounds what might be called the naïve view of mindfulness and compassion. The naïve view takes it as a given that it is a good thing to cultivate mindfulness and compassion because these virtues are key to improving the quality of life and bettering effective decisionmaking within business. Such a view is here termed "naïve" because it assumes that mindfulness and compassion are straightforward concepts that can simply be taken at face value independent of context. However, considered in the context of profound controversies that surround them, mindfulness and compassion are deeply interpretive concepts - that is, such notions are "thick," involving a blend of factual and normative dimensions. There are clusters of neighboring concepts that influence one's understanding of and existential commitment to contemplative practices such as mindful mediation: the nature of the self; competing social, political, and moral values; one's degree of acceptance or rejection of the dog-eat-dog ethos of modern capitalism. 
As well, the virtue of mindfulness has roots in religious and spiritual traditions, ${ }^{1}$ and the virtue of compassion is complex and contextual; neither of these virtues operate in a vacuum. Nor do they function in some stand-alone way, independently from other virtues and values. Indeed, as I argue, reasonable people of goodwill who possess the virtues of mindfulness and compassion in good measure, may nevertheless strongly disagree about what the compassionate, mindful thing to do is when faced with such a question, particularly in a workplace or business setting.

Not only are other neighboring virtues at play in leading the good life, any one virtue or even a set of virtues, may themselves be controversial in their application to a business dilemma and thus, depending on one's interpretation of that virtue or set of virtues, may influence the way one responds to a given situation in the real world. It is, moreover, conceivable that the intensive cultivation of mindfulness and compassion could lead one to ultimately reject a lifestyle grounded in mainstream materialistic culture - the very kind of cutthroat culture deeply infused into the world of competitive business that, caught up in the modern mindfulness movement, draws upon only those selective features of contemplative practices that may lie in the corporate comfort zone, yet which are not especially countercultural from a religious or spiritual vantage point.

The response I offer to this first broad concern is for Eastern contemplative practice to be open to the critical philosophical standpoint afforded by Western virtue-based business ethics, particularly with regard to a deepened awareness of the contestable nature of interpreting virtues. One might consider in this regard the way Socrates approached the virtues, with a questioning and even at times ironic spirit (Benson 2000).

The second broad concern is that Western virtue-based business ethics is largely confined to academic philosophical theories as are typically studied in college and university philosophy curriculums. As such, virtue-driven business ethics is often more centered around matters of theoretical wisdom than what we might call "hard core" practical wisdom, whereas for contemplative practices the reverse is the case, with practical wisdom ("knowing how-to") being emphasized over theoretical wisdom ("knowing that"). The aim of contemplative practices is not just that one know about a philosophy or even that one know how to philosophize and reason through business ethics case studies. Rather, the objective of contemplative practices is that one live a good life through one's participation in particular disciplines (e.g. yoga, meditation, centering prayer) as a pathway for a better life and for cultivating the art of living well.

To summarize the key questions motivating cross-fertilization, then: Can Western virtue ethics deepen contemplative practice's appreciation of the complexity and sometimes contestable quality of mindfulness and compassion? Can contemplative practices expand the scope of Western virtue ethics beyond theoretical knowledge to encompass the sphere of practical

\footnotetext{
${ }^{1}$ Some scholars contend that the current infatuation with mindfulness unfolding in contemporary business management (as well as in popular culture) is itself more of a Western than Eastern phenomenon. For instance, Robert Scharf, Distinguished Professor of Buddhist Studies at the University of California, Berkeley points out that recent views of mindfulness, especially what this article characterizes below as "present-centered consciousness," are not traditional but derivative of $20^{\text {th }}$ century movements, and that these innovative movements have been subject to criticisms by genuine practitioners of traditional Buddhism. Among other things, critics have pointed out how mindfulness is a popularization intended, in significant part, for non-Buddhists, and consequently involves no essential engagement, as it should, with the content of Buddhist tradition, scripture, or practice. See, e.g., Scharf, 2015. The existence of such critiques supports my claim about the contested nature of mindfulness as an interpretive concept.
} 
knowledge as well? And to focus these questions a bit further still: How should the application of Eastern contemplative practices to business be viewed from the standpoint of Western virtue-based business ethics theory and practice? Is there an opportunity for interpretative cross-fertilization between the Eastern and Western approaches? Or, on the contrary, are the fundamental orientations to ethical theory and practice taken by the two traditions so different as to consign them to talk past each other? For instance, in Aristotle's view, one can be trained or habituated by setting up some virtue as a goal. One concentrates on the goal in the process of training. The assigned virtue is kept in mind as the intended direction, lest the training will fail in the very process enlisted to cultivate virtue. By contrast, some forms of contemplative practice advise one to relax and let go of all thoughts in one's mind, thereby freeing the practitioner from being distracted by these thoughts. Such a practice liberates practitioners from any control, enabling them to remain in the center of all directions. Given such differences between a Western virtue-oriented ethics and an Eastern contemplative or mindfulness-oriented ethics, a critic might doubt whether the two ethical orientations be sufficiently reconciled so as to enable meaningful cross-pollination. In response that criticism, I offer a clarification that by using the term "cross-pollination" it is not meant that there is not necessarily any convenient harmonization obtainable between the two ethical traditions, but rather, an opportunity for a mutually beneficial exchange. Nevertheless, I shall argue that beneath some obvious differences there is a major touchpoint between the Eastern and Western traditions that points in favor of cross-fertilization: their respective focus upon character and self-improvement geared toward the cultivation of greater ethicality.

Accordingly this article proceeds from a philosophical standpoint. It is proposed that in order to assess the possibilities for cross-fertilization between virtue-based ethics and contemplative practices, and to enable such an exchange to be plausibly applied to the business ethics context, both virtue ethics and mindfulness must first be understood within an appropriate epistemological frame of reference. It is an "epistemological" frame of reference (admittedly a Western one) that is proposed because what is at stake are fundamental matters of knowledge: scientific (empirical) versus nonscientific (normative) knowledge, and conceptual (propositional) knowledge ("knowing that") versus experiential ("knowing how-to") knowledge (Bernecker and Pritchard 2011). Such an epistemological standpoint is laid out with the following three themes: (T1) mindfulness and compassion constitute key virtues ${ }^{2}$ within contemplative practices. (T2) the virtues in contemplative practices denote, in the fullest sense, "normative-interpretive" concepts, not simply "empirical-criterial" concepts. (T3) to mitigate against distortion and undervaluation, and to acknowledge the diversity of viewpoints surrounding the nature, cultivation, and cultural context of applications of mindfulness and related virtues to the business sphere, it is important to approach the virtues of contemplative practice not exclusively through scientific-empirical study about physical states of the brain and body, but as well through nonscientific inquiry into normative (interpretive) questions concerning such virtues (questions about meaning, responsibility, reasons for acting, values, the nature of the self, living the good life).

Part 2 sets the stage for presenting the central premises of the article's argument by providing a background sketch on virtue-oriented business ethics. Part 3 gives a brief overview of mindfulness in contemplative practices as applied to business. Part 4 proposes several

\footnotetext{
${ }^{2}$ According to Aristotle, "virtue is a purposive disposition, lying in a mean that is relative to us and determined by a rational principle, and by that which the prudent man would use to determine it." Nicomachean Ethics $1144 \mathrm{~b} 26-7$.
} 
themes concerning a conceptual frame of reference. The central argument is then elaborated in subsequent parts in terms of three points $(\mathrm{P} 1-\mathrm{P} 3)$ which propose perspectives for dealing with the challenges of keeping mindfulness from falling prey to "plain fact" and reductive neuroscientific treatments, and for according appreciation for its practice dimension vis-a-vis cultivating the moral agent's inner disposition to be ethical.

Parts 5 and 6 look in the direction from West to East. Part 5 supports (P1), arguing that a Western virtue ethics interpretation of the virtues of mindfulness and compassion should keep such virtues from being mired in a "plain fact" epistemology that would make a strong dependence upon them philosophically naïve in the sense of being incapable of handling hard cases of the sort typically arising in business ethics dilemmas. Similarly (and looking in the same West-to-East direction), Part 6 supports (P2), showing how a Western virtue ethics understanding of the virtue of mindfulness acts as a shield to protect the normative features of mindfulness from being overpowered by empirical neuroscientific studies, as seen in some efforts to lean on such studies in the applications of mindfulness to the sphere of business management.

Part 7 looks in the opposite direction, from East to West. It supports (P3), showing how Eastern contemplative practice adds a vital ethics-in-practice dimension to virtue ethics that renders it especially adaptable to the business context, particularly as concerns the problem of cultivating an inner disposition to be ethical. Part 8 concludes the analysis.

The analysis does not purport to canvass all features of Western virtue-oriented business ethics that may correlate with Eastern contemplative practices. For instance, Confucianism is not brought into the discussion, although research indicates that it shares many important features with Aristotelian virtue ethics (Koehn 2013). As well, a comprehensive treatment of the incredibly vast reach of Eastern contemplative and philosophical perspectives is beyond the scope of the present analysis. Rather, to lend focus to the analysis, the virtue of compassion - understood as derivative from the virtue of mindfulness - is used to highlight the interpretive character of virtue and to raise concerns about some of the perils of taking an excessively empirical-scientific approach to mindfulness. This is a normative conceptual article. The author does not develop empirical measures of virtue, mindfulness, compassion, or character. Further it needs to be stressed that the cross-fertilization being explored does not suppose that all elements of Eastern contemplative practices can be, nor need to be, conveniently "harmonized" with Western virtue ethics.

\section{Overview of Western Virtue-Oriented Business Ethics}

Virtue ethics is one of three major theories concerning the good life in moral philosophy. The others are consequentialism (especially utilitarianism) and deontology (Anscombe 1997), and all three have been applied to the field of business ethics (Boatright 2012). ${ }^{3}$ Generally speaking, virtue ethics is concerned with both the question "what kind of person should I be?" (an ethics of being) and the question "what should I do?" (an ethics of doing), in contrast to approaches focused on precepts or rules (Athanassoulis 2012, Hursthouse 1997). By centering around the idea of being good as persons, virtue ethics stresses internal motives,

\footnotetext{
${ }^{3}$ Examining the prospects for cross-fertilization between contemplative practices and virtue ethics approaches is not to suggest that similar conceptual paths could not be forged between contemplative practices and deontological or consequentialist approaches. Such an undertaking, however, is beyond the scope of the present article.
} 
attitudes, beliefs, inclinations and desires in moral choice. Virtue ethics addresses the role of character in moral theorizing, and involves a regard for the internal existential dimension of a person's life, as opposed to laying emphasis on adjustment of behavior towards compliance with rules and precepts. As will be shown, such a general orientation towards character and interiority of ethical motivation is taken by contemplative practices focused on mindfulness in Eastern philosophical traditions as well. It is this shared orientation of character and internal motivation that provides a bridge for potential cross-fertilization between contemplative practices and virtue ethics, particularly with regard to their appearance in business management.

Virtue ethics comprehends the good life as an ongoing project - a lifelong pursuit for reflective human beings. Aristotle defines a virtue as a state of character (Aristotle 1999, 1106a 13-14). But what makes up a person's good and virtuous character? Concerning the virtue of compassion, at what point could we say, "now if anyone is a really compassionate manager, she surely is"?

To be a genuinely compassionate moral agent, it is not sufficient for him or her to merely carry out what appear to be actions that assist others. To truly be compassionate, a person must be in possession of the particular kind of feelings and mental states that motivate or drive compassion. Furthermore, a compassionate person would have to experience such inner promptings over and over, as a matter of course. When one has cultivated the disposition for being a caring person, his or her compassion is deeply ingrained. Thus, what it means for an individual to build their character or virtue is basically for him or her to habitually nurture certain emotive reactions, yearnings, and ways of seeing that all cash out as a peculiar sort of attitude or interior disposition. (Alzola 2015; Hartman 2007; Oxley 2012). Consequently, what makes for a compassionate businessperson is not some roster of actions he or she might undertake in the name of, say, promoting corporate philanthropy or a happier, stress-free workplace. Instead, for a businessperson to be compassionate involves that actor having qualities of character appropriate to a compassionate person. It is such qualities that establish the actions required by compassion, and not the other way around.

To develop virtue, businesspersons should look inward to pinpoint whatever character flaws they may have. An executive harboring tendencies toward self-absorption or greediness can try to counterbalance them by focusing on controlling his thoughts and feelings, orienting them instead in the direction of virtues like compassion or generosity. The idea is not just to get people either to undertake or avoid certain kinds of actions (Solomon 1998). Rather, it is to encourage people to cultivate the right sort of habits of heart and mind (Oxley 2012, 170).

Aristotle defines a virtue as a quality or character that equips an object or a person, respectively, to accomplish its principal function well. For a knife to be sharp is that kind of tool's greatest virtue. That is because a dull knife fails to accomplish its primary function of cutting effectively. Regarding humans, what is our characteristic function, and what would enable us to perform our main function well? For Aristotle, our chief function is using reason to deliberate, to make the right decisions, and to handle affairs well. We ought to cultivate virtues that will enable us to suitably carry out this function. Not doing so makes us live badly. Hence, we need virtues in order to live well and to flourish (Athanassoulis 2012, 53-61).

Aristotle contrasts: (a) the value of acting instrumentally from craft knowledge (e.g., the know-how used to make a product), with (b) the value of acting from virtue. In the case of (a), the goodness of production comes from the usefulness involved in making the right kind of product. Yet in the case of (b), the value of virtue does not come from efficient production. Rather, it is intrinsically valuable. The virtuous action has a characteristic motive. The virtuous 
action is not just a means to some further result. Whereas some product might be produced well even if not made by a good craftsman, an action is virtuous only if carried out by a good agent - and resulting from the right state of character (Aristotle 1999, II. 4).

When virtues are understood in this way, developing them is far from simple. Practical reasoning is needed to decide exactly what virtues might be appropriate in various circumstances. Otherwise put, one needs to deliberate about just how to act virtuously at the correct time, place, and manner, pulling it off without veering off into the extremes of an excess or deficiency. Considering the business context, since leaders and the organizations they lead are different, finding themselves in diverse circumstances, leaders will not all be virtuous in the same way (Hartman 2007). Furthermore, various business leaders would not necessarily have to perform precisely the same actions to be deemed virtuous. Virtues are situated, Aristotle argues, in a mean that is relative to us, as opposed to being found in some object. The reason is that people are all different from one another. This suggests that, since business managers and executives are born with their own peculiar abilities, personalities, and life ambitions, the way that each actor may be virtuous will be unique to that particular businessperson. Virtue is, at least in this particular sense, relative to an individual actor's disposition, social circumstance, and orientation for lifetime fulfillment. So each businessperson must use practical reasoning when deciding how he or she ought to act in any given circumstance (Id.).

For Aristotle, the aim of life is eudaimonia or integral human fulfillment. By contrast, for some contemplative practices (such as yoga) the aim of life is depicted as samadhi, or selfrealization. Both contemplative practice and Aristotelian ethics are sometimes framed by critics as self-indulgent enterprises wherein the function of morality or virtuous conduct seems to be fundamentally self-serving. According to Aristotle, eudaimonia is a natural human inclination, one aimed at fulfilling the purpose of life. Given the significance attached to eudaimonia for the individual, critics may assert it is not of itself of any necessary benefit to others. However, it may be argued in response that the virtues are valuable for their own sake, not just instrumentally as a means to eudaimonia. Thus, regardless of whether a virtuous individual succeeds in attaining eudaimonia, he or she will be inclined to treating others well from a love of virtue. Likewise, a response from the side of contemplative practice will be that the cultivation of inner peace and present-centered awareness through meditation - conducted not for mere selfindulgence, but rather for the attainment of samadhi - actually does benefit others, in that the experience is attended by a natural extension of compassion toward other beings.

Virtue ethics stresses that the good life is lived out in a community, among people espousing and cultivating a shared set of virtues. The community constitutes an important feature of virtue ethics in the sense that it establishes some constraints on morality. Consequently, it follows from such an outlook that virtues esteemed by any given business organization - embodied, for instance, in its corporate culture - would influence the virtues its leaders should strive to develop for the business community. Furthermore, it would follow that communities bear some responsibility for encouraging certain virtues, insofar as members of those communities are equipped to practice and cultivate such virtues with accountability (Oxley 2012, 171-172).

\section{Overview of Eastern Contemplative Practices}

Eastern contemplative practices arise out of a wide variety of what may be termed selfcultivation philosophies with origins in India and China. Eastern contemplative practice 
includes a wide variety of practices, with origins ranging from ancient to post-modern, from deeply religious to wholly secular, that assist people in becoming more aware of thoughts, emotions and physical states, and assist people in being more deeply present and capable of choosing responses to stimuli in their environment. Contemplative practices cut across a wide spectrum of undertakings: yoga, qi gong, t'ai chi ch'uan, aikido, lectio divina, chanting, focused breathing, sitting or walking or loving-kindness meditation, and many others (Plante 2010). Adherents to such practices believe they assist in developing self-knowledge, as well as in cultivating awareness of the psychological or emotional states of others.

It is proposed that, in their respective quests to deliver a path toward self-cultivation, ${ }^{4}$ a common feature shared by Eastern contemplative practices is their presupposition of an ethic of mindfulness and its closely connected virtue, compassion. The concept of mindfulness itself is complex, composed of several separate yet interacting fundamental elements. While the nature of mindfulness itself cannot simply be taken at face value and is a controversial "interpretive concept" in the sense clarified later in this article, the basic elements of mindfulness may nevertheless be provisionally described as follows: present-centered consciousness, cognitive flexibility, and moral virtuosity.

\section{Mindfulness as Present-Centered Consciousness}

One key sense of mindfulness in contemplative practice is "a state of being attentive to and aware of what is taking place in the present" (Brown and Ryan 2003, 822). This aspect of mindfulness represents a quality of consciousness termed "bare attention" (Brown et al. 2007). This attention has an open, receptive quality toward what is occurring in the present moment, both internally and externally (Kabat-Zinn 1990). The following description is characteristic:

Being mindful, having mindful awareness, is often defined as a way of intentionally paying attention to the present moment without being swept up by judgments. Practiced in the East and the West, in ancient times and in modern societies, mindful awareness techniques help people move toward well-being by training the mind to focus on moment-to-moment experience (Siegel 2010, 83).

This aspect of mindfulness involves noticing and observing one's own thoughts. Mindful individuals maintain enough distance from their thoughts to view them impartially. This aspect of mindfulness makes it a metacognitive skill, involving cognition about cognition (Kabat-Zinn 1990).

Some might object that the present-centered aspect of mindfulness is narcissistic in its inward focus. As such, it might be argued that mindfulness would tend to fuel egoistic managers, not the kind of altruistic or selfless individuals with qualities of a compassionate moral character demanded for ethical or enlightened management.

\footnotetext{
${ }^{4}$ An issue that has gained a renewed interest in contemporary thought is a set of inquiries regarding the self. This includes fundamental questions such as: "what is the nature of the self?" and "just who is it that I really am?" Concerns surrounding the nature of the self arise in a variety of disciplines and in a variety of guises: within psychology, politics, ethics, metaphysics, cognitive sciences, and so on. It is normal that Eastern self-cultivation philosophies would stress the significance of such issues. Self-cultivation frequently involves: (i) acquiring some knowledge of the self, (ii) more fully becoming a self, (iii) or arriving at a proper relationship with the self. And this is the case even for a philosophy such as Buddhism, which denies the existence of a self, together with Mahayana forms denying that anything actually possesses an intrinsic nature (termed emptiness).
} 
A response is discernible in this statement from Nisargadatta Maharaj: "one who is devoted to his own self becomes the soul of all. Who, then, will have ill will and for whom? One becomes helpful to others naturally knowing that one is not different from them" (Greenblatt $2003,73)$. Inherent in this teaching is a metaphysics in which the small self is dissolved, through yogic practice, into the universal Self. It is there that one experiences that "charity and love are naturally present" (Id., 83).

For an ethics of mindfulness, rather than being something externally imposed, virtue derives from practices that support an expansive and "life-enhancing" vision of oneself "as a divine being full of goodness and greatness" (Id.).

Contemplative practice comprises many different practices, including meditation and selfstudy (or self-attentiveness) that help to dissolve a sense of "I am" as separate from everyone else. From this dissolution of self, in Nisargadatta's words, "compassion will flow through you." (Greenblatt, 56).

Importantly, the above analysis of mindfulness suggests a tight connection between mindfulness and compassion. The rockbed of the virtue of mindfulness that bears directly on ethical management is this: when one gains an awareness of one's expanded nature, one is naturally inclined to treating others well. In efforts spent in pursuit of self-realization, one naturally becomes more ethical. Yet the turn toward ethicality does not stem from duty and is not taken for instrumental reasons, but rather flows from inclination. One comes to a recognition of oneself as being at one with others. This occurs not as a mere theoretical abstraction but as a concrete experience (Macneill 2012, 194).

\section{Mindfulness as Metacognitive Flexibility}

There is a stream of empirical research employing the term "mindfulness" in connection with a type of metacognitive flexibility. In this stream of research, spearheaded by Langer, mindfulness refers to an ability to categorize familiar stimuli in new ways (Langer 1989). Both Langer's conception of mindfulness and the aforementioned conception of present-centered mindfulness relate to thinking that is engaged and open rather than automatic and unexamined. However, there are differences between the two. Langer's approach stresses the ability to perform certain active operations on external stimuli, such as seeking new ways of approaching a familiar task. Present-centered mindfulness, on the other hand, represents a quality of consciousness that is observant, receptive, and non-judging toward one's current experience.

\section{Mindfulness as Moral Virtuosity}

Absent from much of the popular literature on workplace mindfulness (Gelles 2015a, b) is the notion of cultivating an inward, rational understanding of the virtue of mindfulness in the nonreductive and noninstrumental sense. It is proposed that a virtue ethics perspective is necessary in order to understand contemplative practices holistically as an authentic virtue ethic, aimed at integral human fulfillment and the common good, and speaking to individual practitioners, who will wrestle with such practices on their own unique journey.

Contemplative practice is both a kind of system of ethical inquiry and a practical art (Macneill 2012, 188). What has been termed an ethic of mindfulness involves awareness of the interconnectedness of all living beings and the capability of transcending oneself to a heightened level of consciousness. For an ethic of mindfulness, corporate social responsibility 
and sustainability are not instruments to maintain and advance mainstream materialistic business rationales but instead serve as fundamental objectives in their own right (Pruzan 2011; Corner and Pavlovich 2016).

Zajonc posits that contemplative practices can pave the way for moral development. On this path, when one finds oneself in distress, mindfulness gives the tools and dispositional will to dampen egotism as a source of moral confusion, to quiet the passions, and to discern right choices in any circumstance (Zajonc 2009). For Zajonc, contemplative practice can aid one in accessing their innate, universal ethical bearings by assisting in the cultivation of the moods of humility and reverence.

Heightened moral awareness in the business world is tied to one's attraction to and disposition for ethics, sustainability, and corporate social responsibility (Ims and Jakobsen 2011; Corner and Pavlovich 2016). Such a broadened understanding of business motivation sees the motives of business managers to choose and act in harmony with what is understood as true, right, and good as grounded in intrinsic value (Jackson 2012), and fundamentally divergent from expediency motives to choose and act according to what is taken to be instrumentally valuable for advancing short-term and selfish objectives such as hedonism or power.

\section{Epistemological Frame of Reference: Three Themes}

\section{First Theme: (T1) Understanding Mindfulness and Compassion as Virtues}

In light of the previous background discussion, it is posited that mindfulness, along with other character dispositions such as awareness, compassion, sympathy, sensitivity, and lovingkindness, may be characterized (using the language of Western, especially Aristotelian, virtue ethics) as virtues within contemplative practice. The rationale for counting mindfulness and associated qualities like compassion as virtues is that, like other commonly recognized virtues, they denote dispositional character traits that tends to be cultivated and formed over a long time span. While a person's mindfulness and compassion tend to be influenced by various factors, once established, as with other virtues, they tend to be remain stable, predicable and resistent to enticements and distractions. Along with other virtues, the path toward mindfulness is purposefully chosen, it is knowingly pursued for its own sake. Cultivating a virtue such as mindfulness involves developing attitudes, emotions and dispositions both toward oneself and others. Mindfulness is an intellectual and emotive state, and includes a focused awareness of one's mind as the seat of mental activity and an attempt to control one's thoughts and emotions to be more aware.

Mindfulness also is about being able to slow oneself down, controlling the proclivity to dart from one thought to another without reflection, and being aware of the perils of being influenced by stresses and anxieties (Oxley 2012, 173; Macneill 2012, 195). Cultivating an attitude of mindfulness lets one become more calm, thoughtful, and aware of others rather than being selfishly preoccupied with one's mental life. The active component of mindfulness, or exhibiting the virtue of mindfulness outwardly, involves performing actions that exhibit one's attitude of mindfulness. In the business context this may entail showing concern for customers and colleagues, being benevolent and caring toward subordinates, or getting involved in community service and charitable causes (Table 1).

Whether mindfulness should be considered a "cardinal" virtue and whether it is technically an "intellectual," virtue as opposed to a "moral" virtue, are, to be sure, contestable issues. It is 
not necessary to elaborate on such issues, much less resolve them, here. At any rate, the success of the overall argument of this article does not hinge on how these kinds of side issues might be resolved.

\section{Second theme (T2): Understanding the Virtues in Contemplative Practices (Mindfulness, Compassion and so on) as Denoting "Interpretive" Concepts Rather than Criterial or Natural-Kind Concepts}

We may distinguish three kinds of concepts. The first kind are natural-kind concepts, which are used to distinguish natural kinds such as 'tiger.' The second variety of concepts are criterial. The meaning of such concepts are established on the basis of a set of defining criteria, for instance, the criteria for calling something a 'triangle' or a 'book'. For such concepts, disagreement centers around whether or not the given criteria are satisfied (Dworkin 2013, 158). By contrast, interpretive concepts are those for which no fixed criteria or instanceidentifying decision procedure, but normative/evaluative considerations that best justify some total set of practices at hand. Concepts such as 'courtesy' and 'justice' are interpretive in this sense: no fixed set of criteria determines how they apply.

Why is it important to bring this distinction to bear on the present discussion of virtue and contemplative practices? The reason is because moral principles underwriting virtuous conduct as comprehended by contemplative practices are best understood as interpretive concepts. It is particularly noteworthy in this regard that Socrates' dialogues treat ethical questions as centering around criterial concepts - leading to no satisfactory answers when one queries, say "what is justice?" Aristotle, on the other hand, characterizes ethics as more like arts of medicine, navigation, comedy - revolving around interpretive concepts. Ethics is not mathematics, so asking "what is courage?" engages reasonable debate, or dialectic, about competing conceptions of courage (Hartman 2007, 318).

Concerning the concept of mindfulness, if one takes it only as a criterial concept, then one will ask how it should be defined. Certainly, this is an important question that helps to establish a launchpoint for subsequent moral debate. As I suggested earlier in this article, received scholarship suggests various definitions of mindfulness, including present-centered awareness, metacognitive flexibility, and moral virtuosity. By contrast, if one takes mindfulness as an interpretive concept, then a deeper inquiry about its meaning and significance, and justification for whether it should be used for this or that purpose, is called for. Debates about whether secular deployments of mindfulness as a management tool somehow violate the integrity of mindfulness in light of its origins in Buddhist spirituality and other wisdom traditions surpass

Table 1 Summarizes some key points of comparison between Western virtue ethics and Eastern contemplative practice.

Virtue ethics

Focus on practicing virtue and developing character, significance given to inner motivations

Goal of eudaimonia (Aristotle)

Emotions relevant to moral character; emotional control from intellectual and moral virtues

Individual wellbeing tied to wellbeing of others in community
Contemplative practices

Focus on practicing mindfulness, significance given to inner states (e.g. meditation, yoga)

Goal of samadhi

Emotions controlled and observed through mindfulness

Expanded concern for others, movement from self to selflessness conducive to compassion 
questions about defining criteria, engaging instead moral reflection about justifying some total set of practices in the name of mindfulness, properly understood. A substantial amount of the controversy - which has been magnified by the eagerness to transfer mindfulness techniques to the business context - centers around the attendant problems of deracination (uprooting mindfulness from traditional wisdom tradition contexts), secularization (separation from religious and spiritual settings), and instrumentalization (deployment as a tool rather than as an intrinsically valuable pursuit (Rosenbaum and Magid 2016). How one ought to best understand mindfulness and its linkages to attendant virtues such as compassion, then, engages moral questions that cannot be settled at face value as a matter of plain fact or conventional definition.

\section{Third Theme (T3): Understanding Virtues in Contemplative Practices Above and Beyond Nonscientific Inquiry Into Normative (Interpretive) Issues}

This theme is concerned with understanding the virtues associated with mindfulness as something deeper than possessing brain states identified through scientific investigation. Thus, just as virtue ethics may appeal to the notion of the "ideally virtuous agent" (Athanassoulis 2012, 67), mindfulness could, for the sake of argument, appeal to the notion of an "ideally mindful agent." Pursuing this line of thought, it could be posited that, just as the ideally virtuous agent is not simply a person who does the right thing, the notion of an ideally mindful agent appeals not just to what a mindful person would do, but further, to the kind of person that a mindful person is. As with the virtuous moral agent, the mindful moral agent is the sort of person who appreciates, what Aristotle terms the orthos logos. The orthos logos may be taken to mean "according to a correct appreciation of the situation" (Crombie 1962, 539). So understood, the orthos logos - whether one is speaking of an ideally virtuous person or an ideally mindful person (or both) - has to do with both appreciating the situation-specific details of one's circumstances and having the right capability to perceive, understand, judge, and be motivated by particular features of situations (Athanassoulis 2012, 71). There are qualities of moral perception - an ability to discern context sensitivity - and qualities of practical wisdom at work. This point is further elaborated in connection with the limits of neuroscientific inquiry into mindfulness in a subsequent section of this article. The discussion will now turn to elaborating the article's central argument - which proceeds with the following points (P1P3), for which the succeeding parts are devoted:

P1: there is a persistent danger of mindfulness falling prey to "plain fact" conceptions, for instance, emphasizing the benefits of contemplative practices as awakening compassion, environmental awareness, other pro-social attitudes. However, such approaches pose a risk of neglecting the controversial nature of value questions and glossing over the attendant need for justifying moral (i.e. nonfactual) judgments - that is, debatable interpretive issues.

P2: there is likewise a danger of mindfulness being subjected to reductive scientificempirical treatments. Whereas neuroscientific studies portray the fruits of meditation as "brain states," virtues are much more than electrochemical processes.

P3: mindfulness can contribute substantially to the practice dimension often neglected by virtue approaches to business ethics, particularly with regard to offering practical ("on the mat") pathways for cultivating the moral agent's inner disposition to be ethical. 


\section{Perils of Plain Fact Treatments}

A look through much of the popular management literature on mindfulness reveals a persistent tendency to emphasize benefits of contemplative practices as awakening compassion, environmental awareness, other pro-social attitudes. One study of the connection between mindfulness and ethical conduct (cheating) purports to show that "[m]indfulness raises awareness of one's own thought processes, thus greater mindfulness is likely to make justifying larger infractions more difficult (Ruedy and Schweitzer 2010)." The study, which deploys a 15-point Mindful Attention Awareness Scale (MAAS) to measure how present-minded a set of research subjects' awareness is, goes on to argue that a greater degree of selfawareness makes peoples less comfortable in misbehaving. However, to the extent such approaches assume that "ethical behavior" denotes something understood as a matter of plain fact (as opposed to something interpretively complex and thus prone to competing controversial interpretations), such morality-as-plan-fact treatments pose a risk of neglecting the controversial nature of value questions and glossing over the attendant need for justifying moral judgments. In other words, ethical issues are often not so simple as to admit of a straightforward factual identification of conduct as: cheating/not cheating. The problem can be illustrated by reference to the following hypothetical business scenario:

\section{Scenario: Interpreting compassion}

Suppose that your colleague asks your opinion about a proposal s/he has written for a project at your company. Should you be honest and blunt, state the truth about how sloppily researched, unorganized, and poorly written the proposal is? Or should you be discrete and positive instead, praising your colleague's work to protect her/his feelings?

In this scenario, one can ask: which response to your colleague is the "compassionate" one? The problem is that reasonable people can disagree about what being compassionate means, and how compassion should be exercised and balanced against other considerations in different situations. Moreover, while the philosopher Arthur Schopenhauer presented a rigorous account of compassion as the foundation of morality (Schopenhauer 1903), it is not clear that cultivating compassion as such is sufficient for one's comprehensive development as a virtuous and mindful moral agent. As the scenario suggests, other virtues like honesty, loyalty, prudence - and how to interpret and act on them - are also at play. So however "compassion" is interpreted, that virtue may have to be balanced against other virtues and moral values some or all of which may pose their own interpretive challenges - in a situation such as this. Some will say that compassion means caring enough for the colleague to not misrepresent one's opinion in an overprotective way. Others will say that compassion means not being cruel in saying all of what one thinks. To be sure, a compassionate moral agent will be disposed to do what is appropriately compassionate in some set of circumstances. However, rationality and interpretation are engaged too. A compassionate person can distinguish compassion from an excess like dotingness, and knows why compassion is a good thing and vices like besottedness and indifference are not good (Hartman 2007, 317). The point is that it is not enough for a moral agent to turn to contemplative practices in the hopes of developing a heightened sense of "compassion." Compassion, while of primordial importance in moral life, is but one virtue among many others that a moral agent will bring to bear in their everyday dealings. As an illustration, there are countless business ethics dilemmas, such as the Merck River Blindness case, in which promptings of compassion for those in need of a drug to combat illness 
(however "compassion" is construed) must be balanced against other considerations, such as competitiveness and profitability (Arnold et al. 2013, 101).

\title{
Protecting Mindfulness from Neuroscientific Reductionism
}

\begin{abstract}
Scenario: Neuroscience and compassion
Suppose after undergoing controlled "loving-kindness meditation sessions" (LKM), brain scans of participants in a scientific study show heightened activity in the right supramarginal gyrus - a region of the brain associated with compassion. The subjects for the study had been initially selected for having decidedly ambiguous, conflicted or uncertain positions on the morality of abortion. Suppose further that after reaching such a brain state of compassion, research subjects overwhelmingly indicate strong approval for an anti-abortion (pro-life) viewpoint. Or conversely, suppose the research subjects indicate strong support for an abortion rights (pro-choice) viewpoint.
\end{abstract}

In either case, whether the compassion-enhanced subjects were now inclined to be more pro-choice or more pro-life, one can pose the question: would such a scientific discovery settle the deep moral controversies surrounding abortion? Of course this example is purely hypothetical. But even if it was real, such a finding would make no difference to the way one justifies a change in one's moral beliefs (Dworkin 2013, 58). That is, one would not say "I think now, because of the changes to my brain caused by sustained meditation practices, which in turn have increased my compassion, that abortion is permissible (or impermissible)." Instead, one would need to set forth the moral reasons that one thinks now justifies one's changed convictions. For instance, one might point to a comparative drop in compassion for the fetus (say in its earliest stages of development) given an absence of its sentience, or perhaps due to a heightened compassion for the mother, seen as having a superior status of sentience, as compared to the fetus. Alternatively, one might report having instead a heightened awareness of the sentience of the fetus (even in early developmental stages), with a corresponding enhanced recognition of the humanity of the fetus. (For a detailed treatment of how virtue ethics, in contrast to consequentialist and deontological theories, analyzes the complexities attending multiple issues surrounding the morality of abortion, see Hursthouse 1997, 226).

The point is, unless one is an emotivist, the assumed changes in one's subjective feelings of compassion one way or another as a result of meditation (or other contemplative practice) will not by itself resolve a morally controversial issue such as abortion. This does not necessarily mean, however, that the virtue of compassion along with the emotions associated with compassion are irrelevant to moral controversies.

It should be noted, by the way, that the moral issue of abortion figures centrally into numerous business and management decisions, particularly those concerning mutual funds and other investments (Netzly 2018). One particularly dramatic illustration is provided in Badaracco's discussion of Roussel-Uclaf chairman Edouard Sakiz's dilemma in the face of the company's sales of the "French abortion pill" RU 486 (Badaracco 1997: 20-23).

Turning back to the neuroscience and compassion scenario under discussion, the central point to be drawn out is that a cautionary stance is in order with regard to the moral significance of scientific findings about the fruits of contemplative practices.

Looking further into why this matters, suppose a critic of contemplative practices points to psychological studies indicating that, whereas meditation increases cognitive focus - which 
would seem to enhance moral awareness, it thereby narrows rather than broadens awareness which seems to restrict moral awareness. The scientific study explains that focusing is related to activation of the brain's "task positive network." So by inhibiting activation of the "default mode network," or by triggering reciprocal inhibition between social and physical cognitive domains (Jack et al. 2013), meditation might be alleged by a critic to preclude, rather than to facilitate, openness to new ideas or moral concerns of the kind associated with ethical management.

One line of response might seek to meet the criticism directly on the level of empirical research findings. Suppose for the sake of argument that social reasoning about, e.g., the mental states of others is generally associated with an increase in the default mode network and decreased use of the task positive network. Also suppose arguendo that mechanistic reasoning is, by contrast, generally associated with increased use of the task positive network and anti-correlated during conditions of rest. However, while anti-correlations between the default and task positive networks were originally interpreted by scientists to indicate that they worked in opposition, having negative reciprocal relationships (Fox et al. 2005), more recent research suggests that the exact nature of the neural relationship between the two networks is more complicated than a simple obligatory negative reciprocity (Spreng et al. 2010, Boyatzis et al. 2014). Positive correlations or lack of anti-correlations between the two networks have been seen during periods of creative thinking (Ellamil et al. 2011), mind-wandering (Christoff et al. 2009), and nature film watching (Golland et al. 2007). Such a response to the critic, on the level of interpretation of empirical scientific findings, would invite debate back and forth about which kinds of contemplative practices, undertaken in which combinations, do or do not contribute to such and such behaviors that might in turn ultimately be expected to contribute to prosocial objectives of ethical management.

However, for purposes of normative argumentation, such disputes about empirical findings miss the core point about connections between mindfulness, virtue, and business ethics. The virtue of mindfulness - understood as a moral virtue and not simply as an empirically measurable behavioral property - is about character, and is thus not reducible to any particular set of causally deterministic brain states. Indeed, the objective measures of "mindfulness" that some neuroscientific and psychological researchers use are at odds with an intuitive, subjective understanding of what it is to be in a state of mindfulness. One's own understanding of what it means to be mindful is tied to the entirety of one's lived experience in the world.

It is proposed that it is misleading to suppose that neuroscientific studies purporting to represent mindfulness as physical state of a brain, understood as an entity that is processing information, mapping the world, constructing a picture of reality, and so forth - are adequately explaining consciousness and a human agent acting pursuant to profoundly interpretive notions such as reasons, explanations, guilt, freedom, duty, rights, and justice. One part of the problem is that this kind of supposition creates an impression that mindfulness (or consciousness) is merely a physical condition of a brain, and consequently that virtues associated with mindfulness are also readily reducible as such. Depicting the resultant "science" as an explanation of mindfulness is not justified when the scientific findings are essentially reading back into explanations precisely those aspects of the phenomena that are in need of an explanation (Bennett and Hacker 2003). The other part of the problem is that such reductive treatments contribute to the misunderstanding that consciousness and mindfulness and thus attendant virtues of mindfulness as well - are all features of the brain qua behaviorcontrolling mechanism, and not features of persons as the kind of free, complex and responsible agents with moral character that virtue ethics takes them to be.

Moreover, an important limitation for empirical research and for the interpretation of empirical studies on the subject of mindfulness is that some central concepts - including "mindfulness" 
itself - are often ambiguous, making reliable measurements challenging both within studies and when comparing results across studies.

In addition, as explained above, there are different elements of mindfulness. The article is not restricted to the present-centered consciousness aspect of mindfulness. Nor is it restricted to the metacognitive flexibility aspect of mindfulness. Instead the focus is much wider, on the virtue of mindfulness situated within the field of normative virtue ethics. Moreover, being addressed to the virtue of mindfulness, the article is not aimed at any given contemplative practice, such as meditation, and especially not in the instrumental deployments touted in popular literature (Gelles 2015a, b). So whatever the findings of neurological studies reveal concerning brain states and associated external behaviors of particular practices (such as meditation) they are not dispositive on issues within the overall theme of this article, which principally concerns not empirical science but virtue ethics.

Thus, scientific findings purporting to show that some particular form of contemplative practice did not foster the virtue of mindfulness would not repudiate or even dampen the postulates of this article. Rather, such findings suggest that certain behavioral tendencies are correlated or anticorrelated with certain neural states. But virtues are not reducible to causally deterministic mental states and behaviors. Rather, as argued previously, virtues refer to inner states and qualities of character. So if practicing meditation turned out to make research subjects excessively focused to the point of selfishness (a vice), such individuals would have good reason to adjust their practices within the wider scope of their lived existential sphere (e.g., modify the way they meditate; or stop meditating; or supplement meditation with other involvements such as prayer, witnessing, walking in the woods, volunteering at a homeless shelter, etc.) so as to cultivate the virtue of mindfulness (and associated virtues such as compassion, lovingkindness, and so forth) instead.

\section{Cultivating Virtue and Inner Motivations through Practice}

There is an elusive character about the ethical life (concerning responsibilities toward one's own life) and the moral life (concerning responsibilities toward others). In part, this elusiveness is due to the sense in which - as Aristotle stresses - ethics is not science but instead a kind of practical art. Aristotle emphasizes that ethics bears more similarity to navigation and medicine than to mathematics (Hartman 2007, 318).

Recent scholarship in ethics has stressed the overlapping quality of ethical and artistic performative endeavors (Jackson 2017). A key feature of such a comparison of the ethical and artistic spheres concerns the need in both for persistent, sustained practice. As well, both domains involve a pronounced attentiveness to the impact on one's conduct, words, even one's inner thoughts, intentions, and silences, both upon oneself and on others.

What is especially astonishing is that in the Western ethical tradition - and this includes the tradition of virtue ethics - the dominant focus remains on theory ${ }^{5}$ and on guiding principles rather than on practice (Macneill 2012,197) and what may best be termed the embodiment of ethics.

Consider how odd such an exclusively theoretical focus would seem with respect to such undertakings as ballet, theatrical performance, or violin playing. Practitioners - virtuoso

\footnotetext{
${ }^{5}$ Granted, a host of thinkers in the Western philosophical tradition have offered critical assessments of an emphasis on theory, among them Bernard Mandeville, David Hume, Edmund Burke, G.W. F. Hegel, Michael Oakeshott, and many others.
} 
performers - of such arts gradually abandon the rudiments laid down in diagrams of steps, scripts, and technical exercises respectively. To be sure, a musician may invest time in carefully studying scores, reading about a composer's life and times, and analyzing relevant music theory and musicology. But there is much attention paid to the performative dimension, the actual movement of one's fingers on the strings, the physical movement of and pressure exerted on the bow, one's posture and breathing, mood, sharpness of concentration, acoustics of the room and so on, in realizing the intended sounds.

The point being made in drawing the analogy with performance arts is this. For the most part, in the case of business ethics, while there is an intensive focus of theoretical issues and concepts, there is scant attention paid to the actual practice of business activities with ethics that is, to doing the day-to-day details of business virtuously in a visceral context, attaining success in honoring the dignity of others, treating them with compassion - as features elemental to the practice of business as such.

Some of the mindfulness interventions into management, on the other hand, involve participants in taking detailed and concrete steps - breathing, meditating, stretching into various yoga poses - with an eye toward cultivating mindfulness, compassion, lovingkindness and other such virtues.

The following testimony of an academic ethicist and yoga practitioner states the case for giving serious attention to the role contemplative practice can play in enhancing one's practical understanding of ethics:

Yoga and ethics are intrinsic to one another. That is to say, the purpose of yoga is essentially ethical and practicing ethics can be understood as yoga . . . It is through practicing yoga that I find an ease in living ethically in this world: in relating to those I am close to and in my interactions with others in my work-a-day world. . . By profession I am a teacher of ethics. I have been teaching ethics for the last twenty years (in three successive medical schools) and I am a yogi, having been practicing various forms of yoga for more than twenty years. Paradoxically, I believe that it is practicing yoga, rather than studying and teaching ethics, that has given me a better understanding of ethics - or at least a more practical and nuanced understanding (Macneill 2012, 187).

\section{The Influence of Context}

Turning things the other way around, what is noteworthy about the traditional Eastern contemplative practices approach, compared to the Western business ethics approach, is the former's lack of theoretical intricacy. One reason may be that the contexts in which practices such as yoga, tai-chi, Buddhist/Hindu meditation arose did not pose as pronounced moral controversies as today. They arose in cultural contexts where greater homogeneity and overall social harmony existed: Zen in Japan, Buddhism in Bhutan, etc. And they arose in historical contexts that predated the intensive technological advances of today with all of their moral convolutedness: cloning, gene sequencing, Internet, artificial intelligence, cryonics, robotics, and so on. That being said, from the standpoint of a variety of contexts at play, today there are competing orthodoxies, each in their own pursuit of mindfulness, yet in divergent ways, and for radically different objectives. Some Buddhists (and other contemplatives from ancient Eastern disciplines) reject the quest for material possessions as a source of wellbeing at the heart of the mainstream corporate world; mindfulness is pursued to lose the self and its endless desires, cravings, and suffering. Some religious practitioners (e.g. Catholic contemplatives), 
along with Buddhists, reject secular materialism (in the sense of a reductive epistemology, or scientism, that the world is comprised only of physical matter, including the brain as physical object), yet pursue mindfulness as a path to deepened devotion of the divine. By contrast, there are secular writers on mindfulness (Kabat-Zinn 2005; Siegel 2010; Gelles 2015a), who tend to distance mindfulness from the spiritual context, seeking to substantiate its benefits with secular scientific studies of the effect of meditation, especially neuroscience. This has rendered mindfulness acceptable from the medical and therapeutic standpoint, as seen with the success of Mindfulness-Based Stress Reduction (MBSR) programs. And then there are some corporates, along with New Age secular hedonists, who reject the spiritual detachment (from all desire, possessions and the attendant suffering) that is the point of departure for Buddhism's grounding in mindfulness. Mindfulness is pursued to increase focus, effectiveness, profitability, stress reduction of workers, health, happiness, and well-being. So there are important existential questions to confront: Should we continue to look to the rhetoric of science to substantiate mindfulness, thus further legitimating it for corporate (capitalist) purposes? What should our response be to the commodification of mindfulness? Will the continued promotion of mindfulness in the corporation eventually backfire, with executives and employees alike rejecting the competitive capitalistic rat race altogether in seach of samadhi? What is the proper end of the pursuit of mindfulness? Is it a neutral tool that can be used for any end (the mindful sniper, military combatant or hedge-fund manager)? Or is mindfulness necessarily linked to eliminating selfishness, fostering of compassion, and repudiation of materialism?

\section{Cultivating Inner Dispositions and Noninstrumental Intentions}

Some contemplative practices associated with mindfulness may be effective in cultivating the inner disposition of managers, executives and others in an organization to be ethical and accordingly to promote business ethics. As well, it is posited that the pro-social impacts of contemplative practices for both leaders and followers are significant not only as a theoretical matter - that is, as an enhancement of virtue approaches to business ethics - but as a practical activity (Kabat-Zinn 2005).

From the aretaic standpoint of ethics, one's virtues, for instance benevolence and compassion, lead one to act in a way that habitually seeks the good of others (Darwall 2003). For this reason, virtues - understood as behavioral dispositions - are a necessary though not sufficient precondition for ethical management. What is needed as well is cultivation of inner states, attitudes, beliefs, desires, emotions, and inclinations of moral agents, which make up a vital "nonreductive" dimension of virtue ethics conspicuously absent from mainstream "reductive" formulations of virtue approaches to business ethics and organizational research.

According to the reductive view, a virtue is a single linear trait bearing a one-toone correspondence with certain behavior in situations where it is relevant. Thus, under the reductive account, the virtue of benevolence is essentially a disposition to perform actions in accordance with the moral duty of benevolence. By contrast, the nonreductive view denies that a virtue is simply a behavioral disposition. For an action to be from a state of virtue, to count as a sign of a good character, it needs to indicate appropriate inner states (Alzola 2015).

The relevance of contemplative practices to this point is their distinctive focus upon the cultivation of inner states, emotions, and attitudes. As Professor Macneill (quoted above) states it: 
[I]n practicing yoga and working toward the goal of self-realization, we naturally become more ethical, not from duty but from inclination. This is because we discover (or recognize) ourselves to be one - or at least 'at one' - with others, not as a belief, but as a powerful and convincing experience. These realizations can also happen the other way around. By practicing ethical virtues (e.g., compassion, generosity, forbearance, and restraint with others) one can experience oneself as more expansive. It is in this sense that practicing ethics can be understood as yoga (Macneill 2012, 195).

\section{Conclusion}

It is hoped that the analysis provided in this article will pave the way for future research into cross-fertilization of Western virtue ethics and the ethic of mindfulness within Eastern contemplative practices. Among the potential benefits of synthesizing virtue ethics and mindfulness are: (i) Western virtue ethics provides a rich frame of reference for potentially capturing and bringing to the forefront more by way of important ethical features of Eastern contemplative practices - particularly the inner motivation to be ethical for noninstrumental reasons, together with the virtue of mindfulness and associated character traits such as compassion and lovingkindness; (ii) the Eastern contemplative practices tradition of mindfulness provides a practice-based disciplined approach to cultivating virtue absent in many of the predominantly theoretical approaches to Western virtue ethics.

The significance of the arguments advanced in this article in support of the kind of qualified cross-fertilization approach it suggests may be understood from two different directions. Looking in the direction from Western virtue ethics toward Eastern contemplative practices of mindfulness, this article shows that taking a virtue ethics standpoint can illuminate several key ethical dimensions of mindfulness. As well, such a perspective has illustrated the need to mitigate against potential distortions and undervaluations arising when what I called the naïve account of mindfulness is applied to business context. The remedy is found in the proposed frame of reference that identifies the underlying interpretive nature of mindfulness and other virtues associated with it. This shows that portrayals of mindfulness and the various contemporary uses to which mindfulness is put, particularly in the business context, are highly contestable, and should not simply be taken for granted at face value. Reasonable people of good will may disagree about the wisdom and legitimacy of introducing mindfulness into the workplace and into the culture at large. Some may, while acknowledging the drawbacks, welcome these trends. Critics may oppose workplace mindfulness initiatives, contending they are popularizations intended, in significant part, for non-Buddhists and require no real engagement with the content of Buddhist tradition, scripture, or practice. The way to channel such disputes into a fruitful dialogue, I suggest, is by appreciating that the disagreement centers not around some fixed set of criteria for defining "mindfulness" or "virtue" in the empirical scientific sense, but rather from alternative interpretations about the justifying point or purpose of mindfulness and its broader connection to cultivating good moral character and to living the good life, both inside and outside of the sphere of business.

Considered in the opposite direction, looking from mindfulness toward virtue ethics, the article shows how a mindfulness perspective enhances virtue ethics, bringing a distinctive practice dimension potentially valuable for transporting business ethics from the realm of theory into a more practical dimension. Despite its advances, virtue ethics approaches have struggled to provide a workable answer to the question of personal transformation: the inner 
motivation and disposition of individuals to be ethical. Accordingly, the analysis suggests that some of the practical, experiential ("on the mat") aspects of contemplative practices holds promise as a corrective for this problem. Initiatives undertaken by companies to introduce yoga or meditation in the workplace provide concrete illustrations of this.

Nothing in the analysis provided by this article should be taken to suggest that all scientific studies of contemplative practices and of mindfulness (such as neuroscientific research) are misguided as such. Indeed, some such studies provide valuable empirical substantiation for many positive benefits of mindfulness, particularly in the business context (Corner and Pavlovich 2016). Such studies can be effective in repudiating wholesale attacks on contemplative practices by critics motivated by ideological or political antipathies (Gelles 2015a). Rather, the article has aimed to assert the value of drawing upon the Western virtue ethics tradition in situating the moral core of mindfulness within the scope of an ethics of character and wellbeing, thereby helping to keep the vital ethical nature of contemplative practices from being obscured or diminished by the epistemic limits of scientific inquiry.

\section{Compliance with ethical standards}

Conflict of Interest On behalf of all authors, the corresponding author states that there is no conflict of interest.

\section{References}

Alzola, M. 2012. The Possibility of Virtue. Business Ethics Quarterly 22 (2): 377-404.

Alzola, M. 2015. Virtuous Persons and Virtuous Actions in Business Ethics and Organizational Research. Business Ethics Quarterly 25 (3): 287-318.

Alzola, M. 2017. Character-Based Business Ethics. In The Oxford Handbook of Virtue, ed. N. Snow. New York: Oxford University Press.

Anscombe, G.E.M. 1997. Modern Moral Philosophy. In Virtue Ethics, ed. R. Crisp and M. Slote, 26-44. Oxford, UK: Oxford University Press.

Aristotle. 1999. Nicomachean Ethics. T.H. Irwin trans., Indianapolis, IN: Hackett Publishing Company.

Arjoon, S., A. Turriago-Hoyos, and U. Thoene. 2015. Virtuousness and the Common Good as a Conceptual Framework for Harmonizing the Goals of the Individual, Organizations, and the Economy. Journal of Business Ethics: 1-21.

Arnold, D., T. Beauchamp, and N. Bowie. 2013. Ethical Theory and Business. 9th ed Pearson.

Athanassoulis, N. 2012. Virtue Ethics. London, UK: Bloomsbury Academic.

Audi, R. 2012. Virtue Ethics as a Resource in Business. Business Ethics Quarterly 22 (2): 273-291.

Badaracco, J. 1997. Defining Moments: When Managers Must Chose Between Right and Right. In Boston: Harvard Business Review Press.

Beadle, R., and G. Moore. 2006. MacIntyre on Virtue and Organization. Organization Studies 27 (3): 323-340.

Bennett, M.R., and P.M.S. Hacker. 2003. Philosophical Foundations of Neuroscience. Oxford, UK.: WileyBlackwell.

Benson, H.H. 2000. Socratic Wisdom: The Model of Knowledge in Plato's Early Dialogues. In New York: Oxford University Press.

Bernecker, S., and D. Pritchard. 2011. The Routledge Companion to Epistemology. London, UK.: Routledge.

Boatright, J. 2012. Ethics and the Conduct of Business. Upper Saddle River, NJ: Prentice-Hall.

Boyatzis, R., K. Rochford, and A.I. Jack. 2014. Antagonistic Neural Networks Underlying Differentiated Leadership Roles. Frontiers in Human Neuroscience 8: 114.

Brown, K.W., and R.M. Ryan. 2003. The Benefits of Being Present: Mindfulness and its Role in Psychological Well-Being. Journal of Personality and Social Psychology 84 (4): 822-848.

Brown, K.W., R.M. Ryan, and J.D. Creswell. 2007. Mindfulness: Theoretical Foundations and Evidence for its Salutary Effects. Psychological Inquiry 18 (4): 211-237.

Christoff, K., A.M. Gordon, J. Smallwood, R. Smith, et al. 2009. Experience Sampling During fMRI Reveals Default Network and Executive System Contributions to Mind Wandering. Proceedings of the National Academy of Sciences USA 106: 8719-8724. 
Corner, P.D. 2009. Workplace Spirituality and Business Ethics: Insights From an Eastern Spiritual Tradition. Journal of Business Ethics 85: 377-389.

Corner, P.D., and K. Pavlovich. 2016. Shared Value Through Inner Knowledge Creation. Journal of Business Ethics 135: 543-555.

Crombie, I.M. 1962. An Exegetical Point in Aristotle's Nicomachean Ethics. Mind 284: 539-540.

Dalai, Lama. 2011. How to Be Compassionate: A Handbook for Creating Inner Peace and a Happier World. In New York: Simon and Schuster.

Darwall, S., ed. 2003. Virtue Ethics. Oxford, UK: Blackwell.

Destino, D. 2015. The Kindness Cure. The Atlantic (July 21).

Dworkin, R. 2013. Justice for Hedgehogs. Cambridge. In MA.: Harvard University Press.

Ellamil, M., C. Dobson, M. Beeman, and K. Christoff. 2011. Evaluative and Generative Modes of Thought During the Creative Process. Neurolmage 59: 1783-1794.

Fox, M.D., A.Z. Snyder, J.L. Vincent, M. Corbetta, et al. 2005. The Human Brain is Intrinsically Organized Into Dynamic, Anticorrelated Functional Networks. Procedings of the National Academy of Sciences USA 102: 9673-9678.

Gelles, D. 2015a. Mindful Work: How Meditation Is Changing Business From the Inside Out. New York: Houghton Mifflin Harcourt.

Gelles, D. 2015b. At Aetna, a C.E.O.'s Management By Mantra. February 27. The New York Times, Business Day http://www.nytimes.com/2015/03/01/business/at-aetna-a-ceos-management-by-mantra.html? r=0

Golland, Y., S. Bentin, H. Gelbard, Y. Benjamini, et al. 2007. Extrinsic and Intrinsic Systems in the Posterior Cortex of the Human Brain Revealed During Natural Sensory Stimulation. Cerebral Cortex 17: 766-777.

Greenblatt, M., ed. 2003. The Wisdom Teachings of Nisargadatta Maharaj. Carlsbad, CA: Inner Directions.

Hartman, E.M. 2007. Socratic Questions and Aristotelian Answers: A Virtue-Based Approach to Business Ethics. Journal of Business Ethics 78: 313-328.

Hursthouse, R. 1997. Virtue Theory and Abortion. In Virtue Ethics, ed. R. Crisp and M. Slote, 217-238. Oxford, UK: Oxford University Press.

Ims, K. and Jakobsen, O. 2011. Deep Authenticity - An Essential Phenomenon in the Web of Life. In A. Tencati and F. Perrini, eds., Business Ethics and Corporate Sustainability. Cheltenham, UK : Edward Elgar.

Jack, A.I., A.J. Dawson, and M. Norr. 2013. Seeing Human: Distinct and Overlapping Neural Signatures Associated With Two Forms of Dehumanization. NeuroImage 79 (1): 313-328.

Jackson, K.T. 2012. Virtuosity in Business: Invisible Law Guiding the Invisible Hand Philadelphia. In PA: University of Pennsylvania Press.

Jackson, K.T. 2017. Music and Virtuosity: A Higher Vision for Business. Humanistic Management Journal 2 (1): 15-36.

Kabat-Zinn, J. 1990. Full Catastrophe Living: Using the Wisdom of Your Body and Mind to Face Stress, Pain, and Illness. New York: Dell Publishing.

Kabat-Zinn, J. 2005. Coming To Our Senses: Healing Ourselves and the World Through Mindfulness. New York: Hyperion.

Kabat-Zinn, J., et al. 1992. Effectiveness of Meditation-Based Stress Reduction Program in the Treatment of Anxiety Disorders. In American Journal of Psychiatry.

Koehn, D. 1998 Virtue Ethics, the Firm, and Moral Psychology. Business Ethics Quarterly 8: 497-513.

Koehn, D. 2013. East Meets West: Toward a Universal Ethic of Virtue for Global Business. 116(4) Journal of Business Ethics.

Langer, E.J. 1989. Mindfulness. Reading, MA: Addison-Wesley Publishing Company.

MacIntyre, A. 2007. After Virtue. 3d ed. London: Duckworth.

Macneill, P.H. 2012. Yoga and Ethics: The Importance of Practice. In Yoga: Philosophy for Everyone, ed. L.S. Swan and F. Allhoff. Oxford, UK: Wiley.

Moberg, D. 1999. The Big Five and Organizational Virtue. Business Ethics Quarterly 9: 245-272.

Moore, G. 2005. Corporate Character: Modern Virtue Ethics and the Virtuous Corporation. Business Ethics Quarterly 15 (4): 659-685.

Moore, G. 2015. Corporate Character, Corporate Virtues. Business Ethics: A European Review 24 (52): $99-114$.

Netzly, R. 2018. Are Your Investments Pro-Life or Pro-Abortion? https:/www.inspireinvesting.com/2018/01/19 /are-your-investments-pro-life-or-pro-abortion. Accessed May 15, 2018.

Oxley, J. 2012. Yoga Off the Mat. In Yoga: Philosophy for Everyone, ed. L.S. Swan and F. Allhoff. Oxford, UK: Wiley.

Plante, T.G., ed. 2010. Contemplative Practices in Action: Spirituality, Meditation, and Health. Westport, CT: Praeger/Greenwood.

Pruzan, P. 2011. Spiritually-Based Leadership. In The Palgrave Handbook of Spirituality and Business, ed. L. Bouckaert and L. Zsolnai. London, UK: Palgrave Macmillan. 
Rosenbaum, R.M. and Magid, B. 2016. What's Wrong With Mindfulness (and What Isn't). Somerville, MA: Wisdom Publications, Inc.

Ruedy, N.E., and M.E. Schweitzer. 2010. In the Moment: the Effect of Mindfulness on Ethical Decision Making. Journal of Business Ethics 95: 73-87.

Scharf, R.H. 2015. Is Mindfulness Buddhist? and Why It Matters. Transcultural Psychiatry 52 (4): 470-484.

Schopenhauer, A. 1903. The Basis of Morality. London: Swan Sonnenschein \& Co..

Siegel, D. 2010. Mindsight: The New Science of Personal Transformation. In New York: Random House.

Sison, A.J.G. and J. Fontrodona, J. 2012. The Common Good of the Firm in the Aristotelian-Thomistic Tradition. Business Ethics Quarterly 22(2): 211-246.

Solomon, R.C. 1997. Ethics and Excellence. In New York: Oxford University Press.

Solomon, R.C. 1998. The Moral Psychology of Business: Care and Compassion in the Corporation. Business Ethics Quarterly 8 (3): 515-533.

Spreng, R.N., W.D. Stevens, J.P. Chamberlain, A.W. Gilmore, et al. 2010. Default Network Activity, Coupled With the Frontoparietal Control Network, Supports Goal-Directed Cognition. NeuroImage 53: 303-317.

Whetstone, J. 2001. How Virtue Fits Within Business Ethics. Journal of Business Ethics 33 (2): 101-115.

Zajonc, A. 2009. Mediation As Contemplative Inquiry: When Knowing Becomes Love. Stockbridge, MA: West Lindisfarne Press. 